\title{
Over-the-scope clip for anastomotic leak after total gastrectomy
}

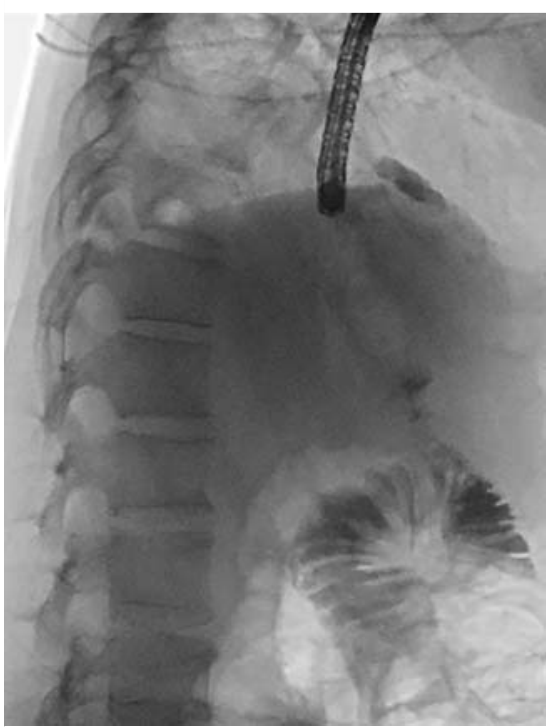

- Fig. 1 Fluoroscopic view. Contrast extravasation at the esophagojejunal anastomosis.

A 57-year-old man who underwent total gastrectomy for gastric adenocarcinoma presented with fever and elevated inflammatory markers on postoperative day 2 . Computed tomography (CT) scan and esophagogastroduodenoscopy (EGD) were unremarkable. The patient devel- oped an evisceration and intra-abdominal infected collection, which was managed with a new surgical intervention and antibiotic treatment. He was discharged on postoperative day 33.

However, 1 week later he was admitted with persistent fever and dyspnea. CT scan confirmed a left subphrenic collection. EGD with fluoroscopic guidance (after contrast extravasation, $>$ Fig. 1) revealed a $3-\mathrm{mm}$ leak located $3 \mathrm{~mm}$ away from the anastomosis ( Fig. 2 a), with abundant purulent drainage ( Fig. 2 b). Endoscopic closure with an over-thescope clip (OTSC) was successful ( $\triangleright$ Fig. 3, $\triangleright$ Video 1 ) and the patient was discharged 7 days later. At the 3-month follow-up, he was asymptomatic.

Postsurgical leaks are an important complication with significant morbidity and mortality. Conservative and surgical management of this complication are also associated with high morbidity and mortality. Several endoscopic treatments, such as stents, OTSC/clips, suturing devices, tissue sealants, and endoluminal vacuum therapy, have shown efficacy and a favorable safety profile [1,2]. Management of postoperative esophagojejunal anastomotic leakage after total gastrectomy represents a very challenging event $[3,4]$. In this case, OTSC application was effective, with no early or late complications.

Endoscopy_UCTN_Code_TTT_1AO_2AI

Competing interests

The authors declare that they have no conflict of interest.

The authors

Pedro Currais, Susana Mão de Ferro, Joana Castela, António Dias Pereira

Gastrenterologia, Instituto Português de Oncologia de Lisboa Francisco Gentil, Lisbon, Portugal

\section{Corresponding author}

\section{Pedro Currais, MD}

Gastrenterologia, Instituto Português de Oncologia de Lisboa Francisco Gentil, Rua Prof. Lima Basto, 1099-023 Lisbon, Portugal Fax: +351-21-7248756 pedro_currais@live.com.pt

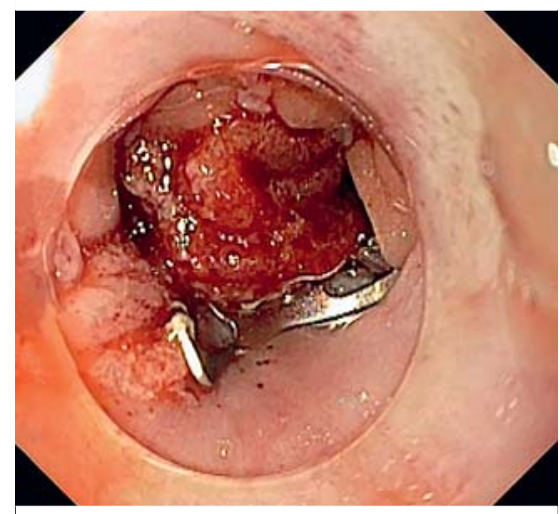

Fig. 3 An over-the-scope clip was deployed for leak closure.
- Fig. 2 Endoscopic view. a Identification of a 3-mm leak, 3-mm away from the esophagojejunal anastomosis. b Abundant purulent drainage from the anastomotic leak.






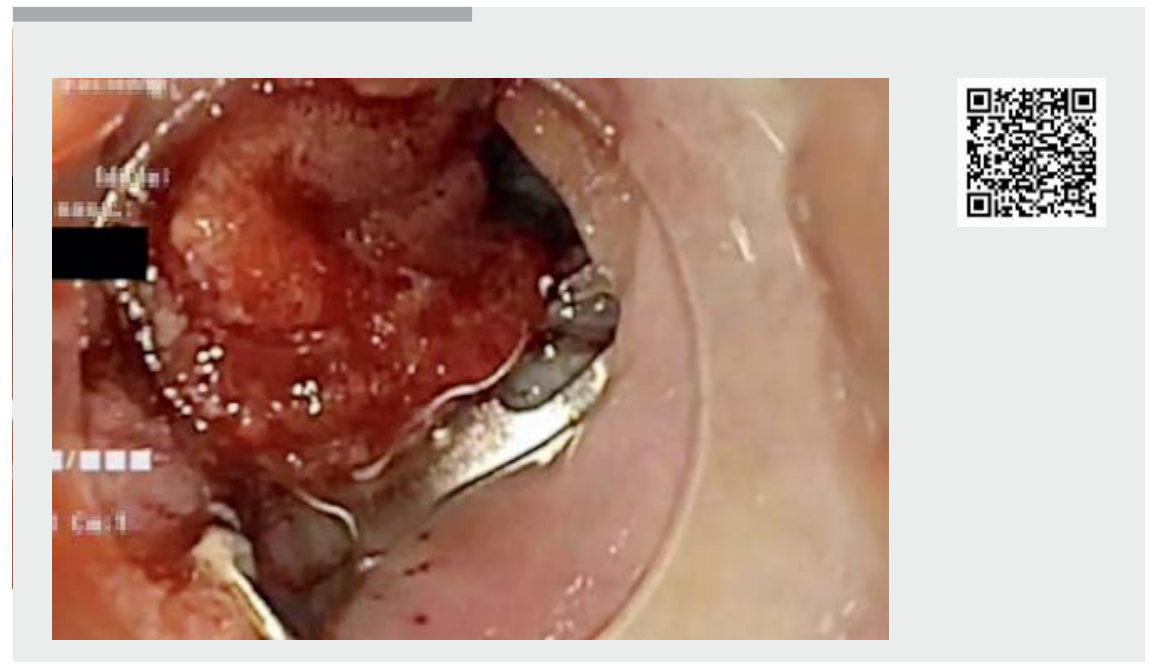

Video 1 Use of an over-the-scope clip for anastomotic leak after total gastrectomy.

\section{References}

[1] Willingham FF, Buscaglia JM. Endoscopic management of gastrointestinal leaks and fistulae. Clin Gastroenterol Hepatol 2015; 13: 1714-1721

[2] Ward MA, Hassan T, Burdick JS et al. Endoscopic vacuum assisted wound closure (EVAC) device to treat esophageal and gastric leaks: assessing time to proficiency and cost. Surg Endosc 2019; 33: 3970-3975
[3] Carboni F, Valle M, Federici O et al. Esophagojejunal anastomosis leakage after total gastrectomy for esophagogastric junction adenocarcinoma: options of treatment. J Gastrointest Oncol 2016; 7: 515-522

[4] Makino H, Nomura S, Maruyama H et al. Endoscopic application of clipping, over-thescope clip (OTSC) and stenting for a fistula and anastomotic leakage of upper gastrointestinal tract. Integr Cancer Sci Ther 2019; 6: $1-5$
Bibliography

DOI https://doi.org/10.1055/a-1122-8086

Published online: 4.3.2020

Endoscopy 2020; 52: E326-E327

(c) Georg Thieme Verlag KC

Stuttgart · New York

ISSN 0013-726X

\section{ENDOSCOPY E-VIDEOS}

https://eref.thieme.de/e-videos

回回 Endoscopy E-Videos is a free

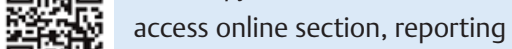
靣辌: on interesting cases and new techniques in gastroenterological endoscopy. All papers include a high quality video and all contributions are freely accessible online.

This section has its own submission website at https://mc.manuscriptcentral.com/e-videos 